\title{
Addressing Clinical Inertia in Type 2 Diabetes Mellitus: A Review
}

\author{
Jennifer Okemah (D) · John Peng · Manuel Quiñones
}

Received: July 5, 2018 / Published online: October 29, 2018

(C) The Author(s) 2018

\section{ABSTRACT}

The current epidemic of type 2 diabetes (T2D) represents a significant global and national health concern. Globally, the prevalence of diabetes has doubled between 1980 and 2014 . In 2014 the World Health Organization estimated that there were 422 million adults living with diabetes worldwide. In the USA, the number of people diagnosed with T2D is estimated to increase to over 70 million by 2050 , putting an immense strain on the US healthcare system. Achieving glycemic control is widely acknowledged as the key goal of treatment in T2D and is critical for reducing the onset and progression of diabetes-related complications such as cardiovascular diseases, neuropathies, retinopathies, and nephropathies. Despite the increase in the availability of antihyperglycemic medications and evidence-based treatment

Enhanced digital features To view enhanced digital features for this article go to https://doi.org/10.6084/ m9.figshare.7200860.

J. Okemah ( $\square)$

Western Washington Medical Group, Diabetes and

Nutrition Education, Bothell, WA, USA

e-mail: jenoke@comcast.net

J. Peng

Virginia Mason Medical Center, Lynnwood, WA, USA

M. Quiñones

HealthCare Partners, Anaheim, CA, USA guidelines, the proportion of people with T2D who fail to achieve glycemic goals continues to rise. One major contributor is a delay in treatment intensification despite suboptimal glycemic control, referred to as clinical or therapeutic inertia. Clinical inertia prolongs the duration of patients' hyperglycemia which subsequently puts them at increased risk of diabetes-associated complications and reduced life expectancy. Clinical inertia results from a complex interaction between patient, healthcare providers, and healthcare system barriers that need to be addressed together, rather than as separate entities. In this article we provide an overview of clinical inertia in the clinical management of T2D and provide suggestions for overcoming aspects that may have a negative impact on patient care.

Funding: Sanofi US, Inc.

Keywords: Clinical inertia; Therapeutic inertia; Treatment intensification; Type 2 diabetes

\section{INTRODUCTION}

Despite the development of new medications over the past decade, a significant proportion of people with type 2 diabetes (T2D) fail to achieve glycemic goals [1]. For example, in the USA, the proportion of patients who achieved the American Diabetes Association (ADA) 
recommended target of glycated hemoglobin $\mathrm{A}_{1 \mathrm{c}}$ (A1C) below $7.0 \%$ declined from $52.2 \%$ between 2007 and 2010 to $50.9 \%$ between 2011 and 2014. Likewise, the proportion of those achieving individualized A1C targets (based on age and diabetes-related comorbidities) declined from $69.8 \%$ between 2007 and 2010 to $63.8 \%$ between 2011 and 2014 [1]. Similarly, across Europe the retrospective GUIDANCE study showed that despite access to new efficacious medications only $53.6 \%$ of patients successfully achieved a target A1C of below 7.0\% [2].

In the context of diabetes, clinical or therapeutic inertia is when patients do not begin or intensify treatment despite not achieving their A1C goal. This can lead to a significant proportion of patients (approximately 30-50\%) experiencing years of suboptimal glycemic control before treatment is escalated [3]. The causes of clinical inertia are multifactorial and complex, and this phenomenon is becoming increasingly recognized in the management of diabetes as well as other chronic diseases [3-9]. Clinical inertia in diabetes results in prolonged periods of uncontrolled hyperglycemia and increases the risk of diabetes-associated complications and reduces life expectancy $[3,8,10-14]$. A study on a large cohort of patients with T2D followed over a period of 22 years showed that a 1-year delay in treatment intensification in patients, on either oral antidiabetes medications (OADs) or insulin therapy whose A1C persisted above $7.0 \%$, significantly increased the risk of myocardial infarction, heart failure, stroke, and a composite of cardiovascular events (Fig. 1) [8, 14]. Furthermore, it has been estimated that inadequate glycemic control is responsible for over 200,000 diabetes-related complications per year in North America alone, resulting in excess healthcare costs and tens of thousands of premature deaths [15]. Globally, the worldwide mortality burden for high blood glucose in 2012 was estimated to be 3.7 million and the global financial burden of diabetes between 2011 and 2030 is projected to be US $\$ 1.7$ trillion $[16,17]$.

The problem of clinical inertia appears to hinder escalation of treatment from OADs to insulin therapy, with delays of approximately 6

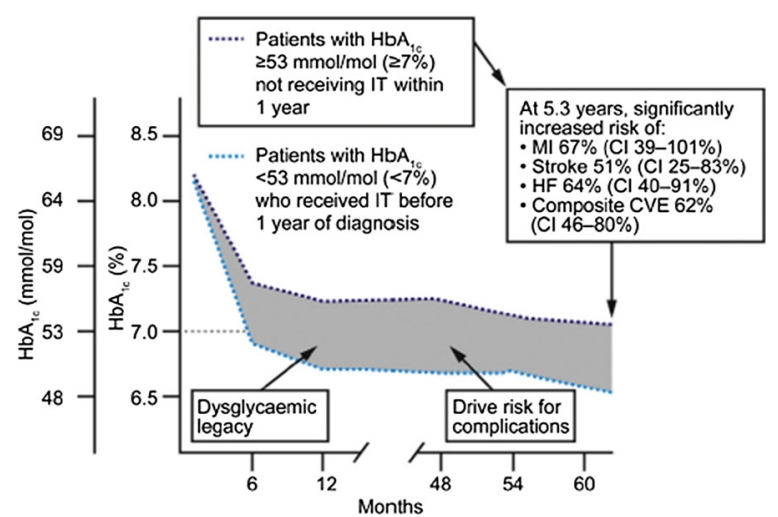

Fig. 1 Consequences of delayed intervention in patients without previous CVD. Reproduced with permission from Khunti. K \& Millar-Jones. D. Clinical inertia to insulin initiation and intensification in the UK: A focused literature review. Primary Care Diabetes. 2017, 11: 3-12 [8] (C) 2016 The Authors. The risk of CVD is shown for patients with $\mathrm{HbAlc}$ consistently above $53 \mathrm{mmol} / \mathrm{mol}$ $(>7.0 \%)$ in the 2 years following diagnosis for whom treatment intensification is delayed by at least 1 year versus that of patients with HbAlc consistently below $53 \mathrm{mmol} / \mathrm{mol}(<7.0 \%)$ in the same period [14]. CI confidence interval, CVD cardiovascular disease, CVE cardiovascular event, HbAlc, glycated hemoglobin, HF heart failure, IT intensification of treatment, MI myocardial infarction. Illustration based on data from [14]. This article is distributed under the terms of the Creative Commons Attribution 4.0 International License (http:// creativecommons.org/licenses/by/4.0/)

to 8 years $[3,8]$. Failure to intensify treatment may also occur in patients who are optimized on basal insulin, but still fail to reach A1C targets despite achieving fasting plasma glucose (FPG) within target ranges. A retrospective cohort study involving 11,696 patients with T2D in the UK Clinical Practice Research Datalink database reported that only $30.9 \%$ of patients with $\mathrm{A} 1 \mathrm{C}$ of at least $7.5 \%$ (i.e., eligible for treatment intensification) had their treatment regimen intensified with bolus or premix insulin or a glucagon-like peptide 1 receptor agonist (GLP-1 RA), and the median time to intensification was 3.7 years [18]. A similar realworld study in the USA reported that, in patients with an index A1C of at least 7\%, who were on a stable regimen of two OADs for at least 6 months, there was a failure to intensify treatment within 6 months in $62.9 \%(n=7389)$ 
of patients [19]. Another recent US study used electronic medical records to show that the likelihood of achieving glycemic goals of A1C below $7.0 \%$ in $\mathrm{T} 2 \mathrm{D}$ patients who initiated basal insulin after OADs diminished considerably if not achieved within 12 months of initiation [20]. As per ADA guidelines, these uncontrolled patients require further intensification by the addition of a single injection of rapid-acting insulin analogue or a GLP-1 RA to target postprandial glucose (PPG) [21]. The use of the recently approved once-daily fixed-ratio combination products containing basal insulin plus a GLP-1 RA, aligned with these guidelines, is another consideration when basal insulin progression is warranted [21].

Clinical inertia is a major concern in T2D [9], and overcoming it is a key step in improving long-term care for people with T2D. This requires an understanding of provider, patient, and healthcare system barriers that need to be addressed together, rather than as separate entities. This review presents an overview of the causes of clinical inertia and describes measures that can be taken to overcome this issue. The information in this article is based on previously conducted studies and does not contain any studies with human participants or animals performed by any of the authors.

\section{CAUSES OF CLINICAL AND THERAPEUTIC INERTIA}

Clinical inertia is multifactorial, with a range of contributing factors from patients, clinicians, and the healthcare delivery system (Fig. 2) [5, 22-27]. Commonly cited factors for both patients and healthcare providers (HCPs) include medication side effects such as fear of hypoglycemia [5, 22-24], concerns regarding weight gain, and the increasing complexity of treatment regimens that require familiarization with new methods of administration and dosing schedules, which could potentially affect patients' daily lives, clinicians' resources, and product costs $[5,23]$. A lack of patient understanding of the nature of their disease can also result in reluctance to intensify treatment. The need to intensify treatment may be associated with the idea that their diabetes has worsened as a result of some "failure" on their part $[5,28]$. Patient willingness to initiate or intensify therapy may also be mitigated by denial about their disease progression and its potential complications, particularly if they have no physical symptoms [27].

Patient concerns can discourage HCPs from initiating or intensifying therapy despite poor glycemic control to avoid offending or losing patients, particularly in areas in which private healthcare predominates [5]. Reports from surveys demonstrate a disconnect between HCPand patient-perceived barriers. HCPs identified fear of hypoglycemia and absence of symptoms as barriers to basal insulin initiation and dose titration, whereas patients reported the length of time taken to reach target as a greater barrier than hypoglycemia [29]. Moreover, patients often get frustrated when they do not achieve glycemic targets, a feeling that increases in parallel with treatment duration and may lead patients to stop medication without discussion with their physician [30]. Finally, physicians often overestimate patient resistance to insulin initiation because of fear of injection-induced pain $[31,32]$.

It is important that HCPs avoid misconceptions of the true nature and degree of patient concerns, as this may result in failure to intensify therapy. HCPs may feel they lack the support, knowledge, and time they need to optimally manage T2D in the face of the ever increasing array of treatment options [15]. Busy providers have limited time available to keep ahead of newly emerging data on available medications that might provide better insight into the best possible outcomes for individual patients. Lack of time and education, together with unfamiliarity with the efficacy and safety of certain regimens, may mean that conventional medications (e.g., metformin, sulfonylureas, and eventually insulin) are more commonly prescribed, while new options, such as combination agents and newly developed medications with potentially greater efficacy, are overlooked.

Healthcare system-related factors that may contribute to clinical inertia involve the lack of individualized clinical guidelines and decision 

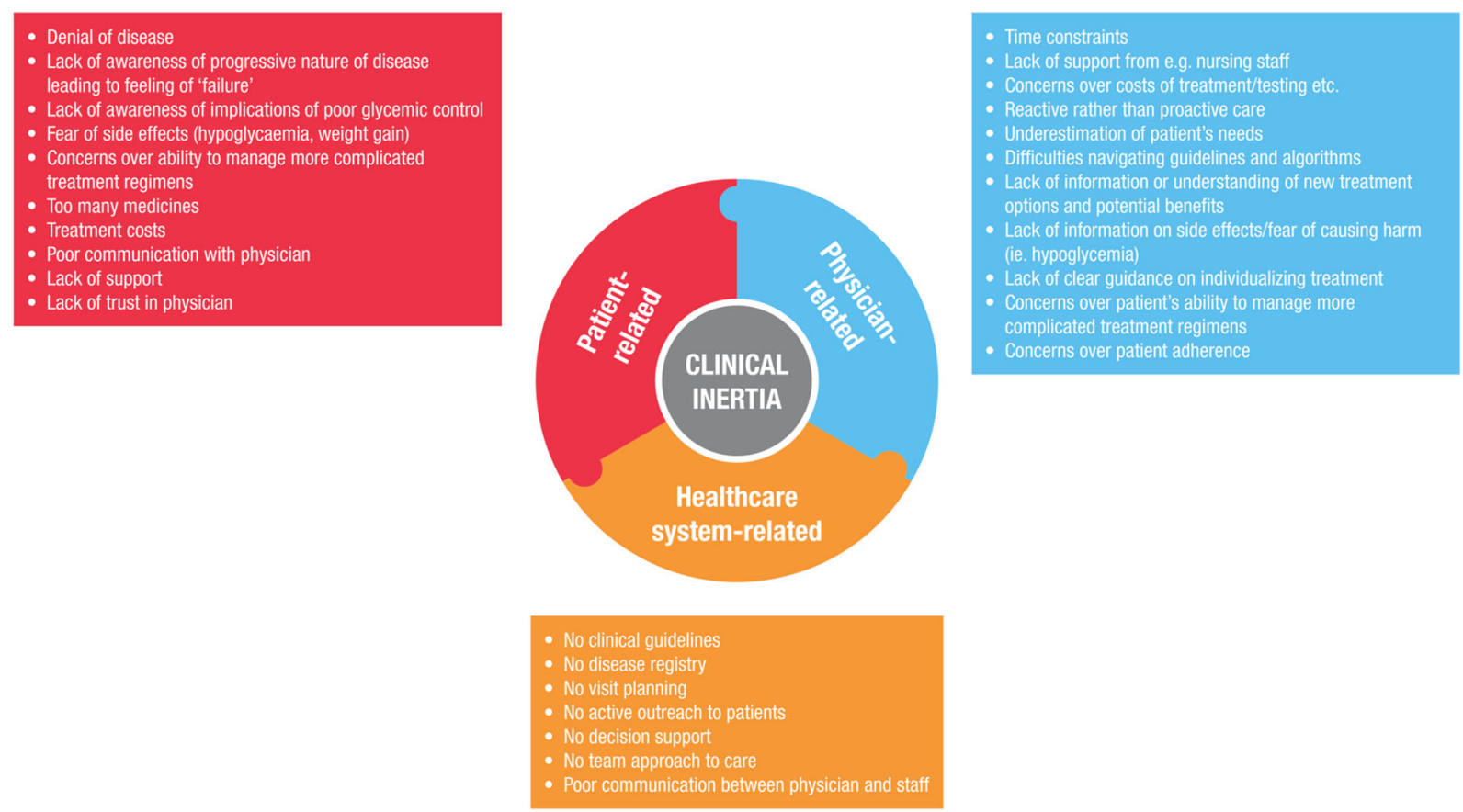

Fig. 2 Patient and physician-related barriers [5, 22-27]

support aids, ineffective communication between physicians and staff, poor patient support systems, and differing region-specific standards that can impact the access to care [27]. Discouragement may arise from the need for authorization of certain medications by health insurance plans or universal healthcare schemes, with potentially expensive and complicated processes around proof of medical necessity and appeals, causing HCPs to resort to using readily approved and generally cheaper medication. Additional issues contributing specifically to provider inertia may include the costs of new medications, complications arising because of discrepancies between pharma-initiated co-pay systems and government-based plans such as Medicare in the USA, and frequent changes in formulary coverage.

\section{ADDRESSING CLINICAL INERTIA}

Although identifying individual underlying causes of clinical inertia is useful, it is important to remember that this is a multifactorial problem and addressing one factor alone is likely to have limited success [15]. It is important that provider-, patient-, and healthcare system-level barriers are considered together rather than as separate problems [25]. We can learn some lessons to combat clinical inertia from randomized clinical trials where set protocols eliminate clinical inertia to avoid confounding the results [15]. The generally superior glycemic control achieved in clinical trials compared with realworld clinical practice is likely to be in part a reflection of the frequency of screening and onstudy contact [15]. While better monitoring of response and regular opportunities to intensify therapy clearly contribute, increased frequency of contact also allows for regular educational input and support, and the development of physician-patient rapport [15]. In addition, trial protocols teach the patient that regular review of therapies is a part of good diabetes care rather than a sign of treatment failure. Overall, the lessons from clinical trials reinforce the need for a combination of good education and support, clear treatment strategies, and more time for interaction between HCPs and patients to reduce clinical inertia. Clinical trials are highly controlled with set protocols, and do not 
necessarily reflect the challenging and diverse real-world clinical situation, but nevertheless provide lessons that can be applied in routine practice.

\section{PATIENT BARRIERS}

HCP-patient relationships and patient support are key to successful management of long-term conditions such as diabetes. As a result of time constraints experienced by providers, patients are often provided with written educational materials without associated interaction, explanation, and encouragement, which have limited effects. Studies have shown that inadequate health literacy can be associated with poor glycemic control, highlighting the need to go beyond written educational material [33-35]. A national literacy assessment in the USA in 2003 concluded that only $12 \%$ of the population had proficient health literacy and $35 \%$ had a basic or below basic level of health literacy [36]. Patient education and support sought through a Certified Diabetes Educator (CDE) is therefore important and may be more successful at addressing clinical inertia. In a recent Canadian study that investigated barriers to care in patients with T2D, the majority of patients with poor glycemic control reported that they did not feel the need for more information regarding the management of diabetes. Their reluctance to acquire and use this information may also be reflected by their reported lack of confidence in their ability to follow through and adhere to treatment [37].

Regular HCP-patient contact and patientcentered, non-judgmental discussions that provide intellectual and emotional support can help overcome patient barriers to adhering and intensifying treatment. Resistance to change can be managed by identifying patient obstacles and actively addressing each one by challenging beliefs, reassuring the patient, and describing reports of positive experiences from patients undergoing the same treatment regime. It is essential that patients understand that diabetes is a progressive disease, and that the addition or intensification of treatment, especially with insulin, is not a failure on their part, but a logical and necessary means of addressing the normal decline in pancreatic function associated with their disease $[5,15,27]$. In a systematic review that included 118 unique diabetes self-management education (DSME) interventions, patients with T2D who received DSME had an average $\mathrm{A} 1 \mathrm{C}$ reduction of $0.57 \%$, demonstrating significant improvements in glycemic control compared to those who did not [38]. Giving praise after improvements in glycemic control and reminding patients of the associated clinical benefits can also help motivate patients [5]. Reluctance to escalate treatment and non-compliance may stem from a lack of knowledge regarding the severity of uncontrolled diabetes and the urgency of reducing $\mathrm{A} 1 \mathrm{C}$ levels and maintaining glycemic control. A recent study demonstrated that physicians were most interested in complications with high rates of mortality, such as cardiovascular disease, whereas patients were more concerned about complications such as retinopathy and nephropathy that would have an impact on the quality of daily living [39]. Patients are more likely to accept and adhere to treatment if they perceive it is contributing to a positive outcome and addressing a need [40]. Therefore, a proactive rather than reactive approach is important in managing patients with diabetes. Emphasis on the association between good glycemic control and lifestyle changes (i.e., diet and exercise) with reduced incidence of complications may prove successful towards improving patient engagement [39]. Moreover, patient fears concerning the negative impacts of certain medications (e.g., use of needles, long-term risks, side effects, treatment complexity, etc.), which may outweigh any benefits, must be addressed [40]. Finally, where the available choices of diabetes medications are similarly efficacious, individualized therapy should be matched to patient preference with respect to convenience, specific side effects, daily dosing schedules, and out-of-pocket costs in parallel to glycemic control [41].

\section{HCP BARRIERS}

For HCPs to successfully support patients through the treatment decision-making process 
and provide optimal long-term care, it is important that provider-related barriers to treatment intensification are also addressed. A study into perceptions of clinical/therapeutic inertia found that most primary care providers were willing to accept a degree of responsibility for clinical inertia, but others tended to avoid accountability by placing emphasis on the negative outcomes associated with patient- and system-level barriers [25]. Providers need to examine and acknowledge whether potential personal issues such as the lack of knowledge of efficacy and safety of agents, resistance to prescribing new medication, skepticism regarding data generated by the pharmaceutical industry, and concerns about costs may influence the management of patient healthcare [25]. The shift of responsibility for diabetes management from secondary to primary care means that HCPs are obliged to keep up to date on new management options and strategies. This becomes particularly important when we consider the differences in prescribing habits that have been previously reported between specialists and primary care providers [27]. A study in France found that specialists were almost 10 times more likely to prescribe early versus late insulin [42]. Readily accessible information is needed on available medications, and particularly new agents, with focus on safety, side effects, efficacy, effectiveness, ease of prescription, purchase, administration, and storage. While there have been numerous studies on the best approach for educating patients with T2D, there is less information available on how to educate and support HCPs. Although evidencebased target guidelines are generally seen as "enablers" for primary care practitioners, their potential for improving clinical inertia is impacted by difficulties with navigating guidelines and algorithms, in keeping up to date with changing recommendations and new treatments, and in interpreting and implementing evidence from trials $[25,26]$. An effective approach would be to provide HCPs with a concise and readily accessible central resource, e.g., the "Wise List" in Sweden, which summarizes the recommended core medicines that should be used in the treatment of common diseases such as diabetes. The use of this list in conjunction with regular monitoring of physician prescribing demonstrated an improvement in adherence to the treatment guidelines [43].

Another recommendation includes more frequent assessment and increased monitoring that is likely to increase physician-patient contact, allowing the physician to determine and address any patient concerns or barriers. However, insurance plans such as the Florida Health Care Plans, time, resources, and costs are factors that limit patient interaction, planning, testing, and prescribing. This can be a problem for solo practitioners or smaller clinics, who may not have access to nursing staff and/or other ancillary support to assist with patient contact such as telephone support and appointment reminders. Time and resource constraints are commonly cited as a source of clinical inertia $[5,25]$. It is likely that time spent optimizing patient management to avoid clinical inertia will ultimately save time, costs, and resources by reducing complications.

While the relationship between the HCP and patient is important, given the pressures on provider time, combating clinical inertia with the aid of CDEs including nurses, dietitians, and pharmacists can be a cost-effective way to influence attitudes and behaviors towards medication and improve clinical care for patients with diabetes [40, 44]. Studies have shown the benefits of assistance from nurses in the management of patients with T2D, including more timely treatment intensification $[7,45]$. DSME programs have proven successful in reducing clinical inertia. For example, patients with diabetes who took part in a 1-year health professional-provided education program were more accepting of their chronic illness and showed improvements in selfmanagement skills and decreased negative emotional response to their disease [46]. Implementing referrals to CDEs and patient support programs do not induce a financial strain on HCPs as reimbursements for these programs are available from the Center for Medicare and Medicaid Services (CMS) and most commercial healthcare plans [47]. 


\section{THERAPEUTIC BARRIERS}

As discussed, several physician- and patient-related barriers to intensifying treatment are associated with limitations (perceived or actual) of therapy. The development of new therapeutic agents has presented physicians and patients with a wider choice of options for adapting treatment to individual requirements. Given the lack of clear guidance from current treatment guidelines on how to individualize therapy, specific information about a specific drug or a combination of medications which certain patients may benefit from may be particularly

Table 1 Mean (SE) change from baseline in glycemic parameters and body weight, and incidence of hypoglycemia and other AEs with options for patients failing to achieve glycemic targets on basal insulin

\begin{tabular}{|c|c|c|c|c|c|c|c|}
\hline & A1C, \% & $\begin{array}{l}\text { FPG, } \\
\mathrm{mmol} / \mathrm{L}\end{array}$ & $\begin{array}{l}\text { 2-h PPG, } \\
\mathrm{mmol} / \mathrm{L}\end{array}$ & $\begin{array}{l}\text { Weight } \\
\text { change, kg }\end{array}$ & $\begin{array}{l}\text { Hypoglycemia, } \\
\text { \% patients }\end{array}$ & $\begin{array}{l}\text { Adverse } \\
\text { events }\end{array}$ & $\begin{array}{l}\text { Number of } \\
\text { injections }\end{array}$ \\
\hline \multicolumn{8}{|l|}{ Basal insulin plus [52] } \\
\hline $\begin{array}{l}\text { RAI with main meal } \\
\text { (basal plus) }\end{array}$ & $-0.6(0.1)$ & $-0.2(0.1)$ & $-1.6(0.6)$ & $+1.0(0.3)$ & $38.9^{\mathrm{a}}$ & & 2 \\
\hline $\begin{array}{l}\text { RAI with each meal } \\
\text { (basal-bolus) }\end{array}$ & $-0.8(0.1)$ & $-0.1(0.1)$ & $-1.4(0.6)$ & $+1.4(0.3)$ & $44.9^{\mathrm{a}}$ & & $3+$ \\
\hline $\begin{array}{l}\text { GLP-1 RA } \\
\text { (lixisenatide) }\end{array}$ & $-0.6(0.1)$ & $-0.2(0.1)$ & $-3.6(0.6)$ & $-0.6(0.3)$ & $32.9^{\mathrm{a}}$ & $\begin{array}{l}\text { Nausea } \\
25.2 \%\end{array}$ & 2 \\
\hline & & & & & & $\begin{array}{c}\text { Diarrhea } \\
6.7 \%\end{array}$ & \\
\hline \multicolumn{8}{|l|}{ Premix insulin [53] } \\
\hline $\begin{array}{l}\text { Biphasic insulin } \\
\text { aspart 30/70 }\end{array}$ & -1.42 & $\begin{array}{r}-1.4(\text { not } \\
\text { reported })\end{array}$ & $\begin{array}{l}\text { Not } \\
\quad \text { reported }\end{array}$ & $\begin{array}{r}+1.7 \text { (not } \\
\text { reported })\end{array}$ & $75.8^{\mathrm{b}}$ & & $2-3$ \\
\hline $\begin{array}{l}\text { Basal insulin/GLP-1 } \\
\text { RA FRC }\end{array}$ & & & & & & & 1 \\
\hline iGlarLixi [54] & $-1.1(0.06)$ & $-0.4(0.1)$ & $-4.7(0.3)$ & $-0.7(0.2)$ & $40.0^{\mathrm{c}}$ & $\begin{array}{c}\text { Nausea } \\
10.4 \% \\
\text { Diarrhea } \\
4.4 \%\end{array}$ & \\
\hline iDegLira [55] & $\begin{array}{l}-1.9 \text { (not } \\
\text { reported) }\end{array}$ & $\begin{array}{l}-3.5 \text { (not } \\
\text { reported) }\end{array}$ & $\begin{array}{l}\text { not } \\
\text { reported }\end{array}$ & $\begin{aligned}-2.7 \text { (not } \\
\text { reported) }\end{aligned}$ & $24.0^{\mathrm{b}}$ & $\begin{array}{c}\text { Nausea } \\
6.5 \% \\
\text { Diarrhea } \\
6.5 \%\end{array}$ & \\
\hline
\end{tabular}

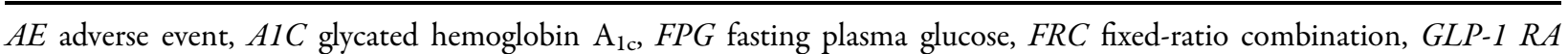
glucagon-like peptide 1 receptor agonist, iDegLira insulin degludec/liraglutide fixed-ratio combination, iGlarLixi insulin glargine/lixisenatide fixed-ratio combination, $P G$ plasma glucose, $P P G$ postprandial glucose, $R A I$ rapid acting insulin, $S E$ standard error

a Symptomatic hypoglycemia accompanied by glucose $<60 \mathrm{mg} / \mathrm{dL}(<3.3 \mathrm{mmol} / \mathrm{L})$ or prompt recovery with oral carbohydrate

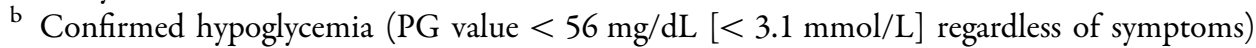

${ }^{c}$ Reported documented symptomatic hypoglycemia $(\mathrm{PG} \leq 60 \mathrm{mg} / \mathrm{dL}[\leq 3.3 \mathrm{mmol} / \mathrm{L}])$ 
useful. This is currently being implemented with recent ADA guidelines recommending lifestyle management and metformin and subsequently incorporating agents such as empagliflozin, canagliflozin, or liraglutide in patients with T2D and established atherosclerotic cardiovascular disease in countries where these agents have been approved for use [21]. Another example of individualized therapy is the management of overweight or obese patients, who may benefit from the use of agents such as GLP1 RAs, sodium-glucose co-transporter-2 (SGLT2) inhibitors, and amylin mimetics which are associated with on-treatment weight loss and avoidance of agents such as sulfonylureas or meglitinides which are associated with weight gain. GLP-1 RAs and inhibitors of the protease dipeptidyl peptidase-4 (DPP-4) are also both associated with a low risk of hypoglycemia because of their glucose-dependent modes of action, and inhibitors of SGLT2 are associated with a low risk of hypoglycemia and reductions in blood pressure [48-50]. Intensification of basal insulin therapy with prandial insulin can be challenging because of fears of weight gain, hypoglycemia risk, and increased treatment complexity, all of which, as discussed, can lead to therapy not being intensified in patients with declining glycemic control. Patients who show such concerns may benefit from treatment with once-daily GLP-1 RA/basal insulin titratable fixed-ratio combinations, such as insulin glargine/lixisenatide (iGlarLixi) or insulin degludec/liraglutide (IDegLira) which show improved glycemic control with reduced hypoglycemia and are either weight neutral or promote weight loss [51], (Table 1). Such combination products also offer the option of escalating therapy without increasing cost and treatment complexity whereby methods of administration would remain unchanged allowing the delivery of both products using a single injection. Some products use the same methods of drug delivery; for example, iGlarLixi uses the same SoloSTAR ${ }^{\circledR}$ (Sanofi-Aventis US, Bridgewater, NJ) pen as insulin glargine to deliver the required dose, meaning that patients would not need to worry about familiarizing themselves with new pens for drug delivery. These options should help to remove some of the barriers causing clinical inertia, but rely on HCPs having knowledge, experience, and confidence in prescribing these medications [8].

\section{CONCLUSION}

Clinical and therapeutic inertia in the treatment of T2D results from HCP-, patient-, and healthcare system-based factors, and represents a serious barrier to optimal treatment escalation and therefore glycemic control. The complex and multifactorial nature of clinical inertia means that one strategy alone is not sufficient to address it, but rather requires addressing a combination of patient-, HCP-, and healthcare system-related barriers. Many patient-related barriers to treatment escalation result from a lack of sufficient education and time to educate patients about disease progression and available treatment. This can be managed by implementing patient referrals to CDEs and patient support programs allowing regular patient-centered, non-judgmental discussions to give both intellectual and emotional support as per ADA Standards of Care [21]. When patients fail to achieve glycemic targets, personalizing therapy to reflect patients' clinical, practical, and emotional needs is likely to improve acceptance. HCPs need to acknowledge and address any personal factors that may result in clinical inertia on their patients' behalf. The introduction of consistent follow-up procedures and improved access to resources along with targeted education of HCPs and patient feedback can help reduce clinical inertia. Support from clinical decision support aids may also help to facilitate treatment. Taken together, such actions should help to minimize clinical and therapeutic inertia and lead to improved treatment outcomes.

\section{ACKNOWLEDGEMENTS}

Funding. Development of the manuscript, Open Access fees and article processing charges were funded by Sanofi US, Inc. All data presented in this study have previously been published and are accessible to all authors. 
Editorial Assistance. Editorial and writing support in the preparation of this manuscript was provided by Yasmin Issop, PhD, and Luke Shelton, PhD, of Excerpta Medica, funded by Sanofi US, Inc.

Authorship. All named authors meet the International Committee of Medical Journal Editors (ICMJE) criteria for authorship for this manuscript, take responsibility for the integrity of the work as a whole, and have given final approval for the version to be published.

Disclosures. Jennifer Okemah has served on advisory boards for DexCom, and Sanofi; participated in speakers' bureaus for DexCom, Insulet CPT, Medtronic CPT, Sanofi, and Sigma. John Peng has served on advisory boards for Sanofi. Manuel Quinones has served on advisory boards for AstraZeneca, Janssen Pharmaceuticals, Novo Nordisk, and Sanofi; participated in speakers' bureaus for AstraZeneca, Janssen Pharmaceuticals, Novo Nordisk, and Sanofi.

Compliance with Ethics Guidelines. The information in this article is based on previously conducted studies and does not contain any studies with human participants or animals performed by any of the authors.

Data Availability. Data sharing is not applicable to this article as no datasets were generated or analyzed during the current study.

Open Access. This article is distributed under the terms of the Creative Commons Attribution-NonCommercial 4.0 International License (http://creativecommons.org/licenses/ by-nc/4.0/), which permits any noncommercial use, distribution, and reproduction in any medium, provided you give appropriate credit to the original author(s) and the source, provide a link to the Creative Commons license, and indicate if changes were made.

\section{REFERENCES}

1. Carls G, Huynh J, Tuttle E, Yee J, Edelman SV. Achievement of glycated hemoglobin goals in the
US remains unchanged through 2014. Diabetes Ther. 2017;8(4):863-73.

2. Stone MA, Charpentier G, Doggen K, et al. Quality of care of people with type 2 diabetes in eight European countries. Diabetes Care. 2013.36(9):2628-38.

3. Blonde L, Aschner P, Bailey C, et al. Gaps and barriers in the control of blood glucose in people with type 2 diabetes. Diab Vasc Dis Res. 2017;14(3):172-83.

4. O'Connor PJ. Improving diabetes care by combating clinical inertia. Health Serv Res. 2005;40(6 Pt 1):1854-61.

5. Ross SA. Breaking down patient and physician barriers to optimize glycemic control in type 2 diabetes. Am J Med. 2013;126(9 Suppl 1):S38-48.

6. Aujoulat I, Jacquemin P, Rietzschel E, et al. Factors associated with clinical inertia: an integrative review. Adv Med Educ Pract. 2014;5:141-7.

7. Khunti S, Davies MJ, Khunti K. Clinical inertia in the management of type 2 diabetes mellitus: a focused literature review. Br J Diabetes Vasc Dis. 2015;15:65-9.

8. Khunti K, Millar-Jones D. Clinical inertia to insulin initiation and intensification in the UK: a focused literature review. Prim Care Diabetes. 2017;11(1):3-12.

9. Khunti K, Gomes MB, Pocock S, et al. Therapeutic inertia in the treatment of hyperglycaemia in patients with type 2 diabetes: a systematic review. Diabetes Obes Metab. 2018;20(2):427-37.

10. Stratton IM, Adler AI, Neil HA, et al. Association of glycaemia with macrovascular and microvascular complications of type 2 diabetes (UKPDS 35): prospective observational study. BMJ. 2000;321(7258):405-12.

11. Goodall G, Sarpong EM, Hayes C, Valentine WJ. The consequences of delaying insulin initiation in UK type 2 diabetes patients failing oral hyperglycaemic agents: a modelling study. BMC Endocr Disord. 2009;9:19.

12. Arnold LW, Wang Z. The HbA1c and all-cause mortality relationship in patients with type 2 diabetes is J-shaped: a meta-analysis of observational studies. Rev Diabet Stud. 2014;11(2):138-52.

13. Paprott R, Schaffrath Rosario A, Busch MA, et al. Association between hemoglobin $A_{1 c}$ and all-cause mortality: results of the mortality follow-up of the German National Health Interview and Examination Survey 1998. Diabetes Care. 2015;38:249-56. 
14. Paul SK, Klein K, Thorsted BL, Wolden ML, Khunti $K$. Delay in treatment intensification increases the risks of cardiovascular events in patients with type 2 diabetes. Cardiovasc Diabetol. 2015;14:100.

15. Strain WD, Blüher M, Paldánius P. Clinical inertia in individualising care for diabetes: is there time to do more in type 2 diabetes? Diabetes Ther. 2014;5(2):347-54.

16. World Health Organisation Global Report on Diabetes 2016. http://www.who.int/diabetes/globalreport/en/. Accessed 30 Sep 2018.

17. Bloom DE, Cafiero ET, Jané-Llopis E, et al. The global economic burden of non-communicable diseases. Geneva: World Economic Forum; 2011.

18. Khunti K, Nikolajsen A, Thorsted BL, Andersen M, Davies MJ, Paul SK. Clinical inertia with regard to intensifying therapy in people with type 2 diabetes treated with basal insulin. Diabetes Obes Metab. 2016;18(4):401-9.

19. Pantalone KM, Misra-Hebert AD, Hobbs TM, et al. Clinical inertia in type 2 diabetes management: evidence from a large, real-world data set. Diabetes Care. 2018;41:e113-4.

20. Blonde L, Meneghini L, Peng XV, et al. Probability of achieving glycemic control with basal insulin in patients with type 2 diabetes in real-world practice in the USA. Diabetes Ther. 2018;9(3):1347-58.

21. American Diabetes Association. Standards of medical care in diabetes-2018. Diabetes Care. 2018;41(Suppl 1):S1-159.

22. Ross SA, Tildesley HD, Ashkenas J. Barriers to effective insulin treatment: the persistence of poor glycemic control in type 2 diabetes. Curr Med Res Opin. 2011;27(Suppl 3):13-20.

23. Peyrot M, Barnett AH, Meneghini LF, SchummDraeger PM. Insulin adherence behaviours and barriers in the multinational global attitudes of patients and physicians in insulin therapy study. Diabet Med. 2012;29(5):682-9.

24. Ahrén B. Avoiding hypoglycemia: a key to success for glucose-lowering therapy in type 2 diabetes. Vasc Health Risk Manag. 2013;9:155-63.

25. Zafar A, Stone MA, Davies MJ, Khunti K. Acknowledging and allocating responsibility for clinical inertia in the management of type 2 diabetes in primary care: a qualitative study. Diabet Med. 2015;32(3):407-13.

26. Phillips LS, Barb D, Yong C, et al. Translating what works: a new approach to improve diabetes management. J Diabetes Sci Technol. 2015;9(4):857-64.
27. Reach G, Pechtner V, Gentilella R, Corcos A, Ceriello A. Clinical inertia and its impact on treatment intensification in people with type 2 diabetes mellitus. Diabetes Metab. 2017;43(6):501-11.

28. Peyrot M, Rubin RR, Lauritzen T, et al. Resistance to insulin therapy among patients and providers: results of the cross-national diabetes attitudes, wishes, and needs (DAWN) study. Diabetes Care. 2005;28(11):2673-9.

29. Berard L, Bonnemaire M, Mical M, Edelman S. Insights into optimal basal insulin titration in type 2 diabetes: results of a quantitative survey. Diabetes Obes Metab. 2018;20(2):301-8.

30. American Association of Clinical Endocrinologists (AACE). Surveys find adults with type 2 diabetes are more willing to take action to achieve A1c targets quicker than physicians and other medical professionals perceive. AACE Online Newsroom. http:// media.aace.com/press-release/surveys-find-adultstype-2-diabetes-are-more-willing-take-actionachieve-a1c-targets-q. Accessed 29 June 2018.

31. Nakar S, Yitzhaki G, Rosenberg R, Vinker S. Transition to insulin in type 2 diabetes: family physicians' misconception of patients' fears contributes to existing barriers. J Diabetes Complications. 2007;21(4):220-6.

32. Yoshioka N, Ishii H, Tajima N, Iwamoto Y, DAWN Japan group. Differences in physician and patient perceptions about insulin therapy for management of type 2 diabetes: the DAWN Japan study. Curr Med Res Opin. 2014;30(2):177-83.

33. Saeed H, Saleem Z, Naeem I, Shahzadi I, Islam M. Impact of health literacy on diabetes outcomes: a cross-sectional study from Lahore, Pakistan. Public Health. 2018;156:8-14.

34. Schillinger D, Grumbach K, Piette J, et al. Association of health literacy with diabetes outcomes. JAMA. 2002;288(4):475-82.

35. Souza JG, Apolinario D, Magaldi RM, Leopold Busse A, Campora F, Jacob-Flinto W. Functional health literacy and glycemic control in older adults with type 2 diabetes: a cross-sectional study. BMJ Open. 2014;4:e004180.

36. US Department of Health and Human Service. America's health literacy: why we need accessible health information. An issue brief from the US Department of Health and Human Services. 2008. https://health.gov/communication/literacy/ issuebrief/. Accessed 30 Sept 2018.

37. McBrien KA, Naugler C, Ivers $\mathrm{N}$, et al. Barriers to care in patients with diabetes and poor glycemic 
control-A cross-sectional survey. PLoS One. 2017;12(5):e0176135.

38. Chrvala CA, Sherr D, Lipman RD. Diabetes selfmanagement education for adults with type 2 diabetes mellitus: a systematic review of the effect on glycemic control. Patient Educ Couns. 2016;99(6):926-43.

39. Vencio S, Paldánius PM, Blüher M, Giannella-Neto D, Caiado-Vencio R, Strain WD. Understanding the barriers and improving care in type 2 diabetes: Brazilian perspective in time to do more in diabetes. Diabetol Metab Syndr. 2017;9:46.

40. Polonsky WH, Henry RR. Poor medication adherence in type 2 diabetes: recognizing the scope of the problem and its key contributors. Patient Prefer Adherence. 2016;10:1299-307.

41. Serrano V, Rodriguez-Gutierrez R, Hargraves I, Gionfriddo MR, Tamhane S, Montori VM. Shared decision-making in the care of individuals with diabetes. Diabet Med. 2016;33(6):742-51.

42. Reach G, Le Pautremat V, Gupta S. Determinants and consequences of insulin initiation for type 2 diabetes in France: analysis of the National Health and Wellness Survey. Patient Prefer Adherence. 2013;7:1007-23.

43. Eriksen J, Gustafsson LL, Ateva K, et al. High adherence to the 'Wise List' treatment recommendations in Stockholm: a 15-year retrospective review of a multifaceted approach promoting rational use of medicines. BMJ Open. 2017;7:e014345.

44. Salisbury C, Fahey T. Overcoming clinical inertia in the management of hypertension. CMAJ. 2006;174(9):1285-6.

45. van Bruggen R, Gorter K, Stolk R, Klungel O, Rutten G. Clinical inertia in general practice: widespread and related to the outcome of diabetes care. Fam Pract. 2009;26(6):428-36.

46. Laursen DH, Christensen KB, Christensen U, Frølich A. Assessment of short and long-term outcomes of diabetes patient education using the health education impact questionnaire (HeiQ). BMC Res Notes. 2017;10(1):213.

47. Powers MA, Bardsley J, Cypress M. Diabetes selfmanagement education and support in type 2 diabetes: a joint position statement of the American
Diabetes Association, the American Association of Diabetes Educators, and the Academy of Nutrition and Dietetics. Clin Diabetes. 2016;34(2):70-80.

48. Garber AJ, Abrahamson MJ, Barzilay JI, et al. Consensus statement by the American Association of Clinical Endocrinologists and American College of Endocrinology on the comprehensive type 2 diabetes management algorithm-2017 Executive Summary. Endocrine Practice. 2018;24(1):91-120.

49. Li J, Gong Y, Li C, Lu Y, Liu Y, Shao Y. Long-term efficacy and safety of sodium-glucose cotransporter2 inhibitors as add-on to metformin treatment in the management of type 2 diabetes mellitus: a meta-analysis. Medicine (Baltimore). 2017;96(27): e7201.

50. Baker WL, Buckley LF, Kelly MS, et al. Effects of sodium-glucose cotransporter 2 inhibitors on 24-hour ambulatory blood pressure: a systematic review and meta-analysis. J Am Heart Assoc. 2017;6(5):e005686.

51. Valentine V, Goldman J, Shubrook JH. Rationale for, initiation and titration of the basal insulin/ GLP-1RA fixed-ratio combination products, IDegLira and IGlarLixi, for the management of type 2 diabetes. Diabetes Ther. 2017;8(4):739-52.

52. Rosenstock J, Guerci B, Hanefeld M, et al. Prandial options to advance basal insulin glargine therapy: testing lixisenatide plus basal insulin versus insulin glulisine either as basal-plus or basal-bolus in type 2 diabetes: the GetGoal Duo-2 trial. Diabetes Care. 2016;39(8):1318-28.

53. Kaneko S, Chow F, Choi DS, et al. Insulin degludec/ insulin aspart versus biphasic insulin aspart 30 in Asian patients with type 2 diabetes inadequately controlled on basal or pre-/self-mixed insulin: a 26-week, randomised, treat-to-target trial. Diabetes Res Clin Pract. 2015;107(1):139-47.

54. Aroda VR, Rosenstock J, Wysham C, et al. Efficacy and safety of LixiLan, a titratable fixed-ratio combination of insulin glargine plus Lixisenatide in type 2 diabetes inadequately controlled on basal insulin and metformin: the LixiLan-L randomized trial. Diabetes Care. 2016;39(11):1972-80.

55. Buse JB, Vilsbøll T, Thurman J, et al. Contribution of liraglutide in the fixed-ratio combination of insulin degludec and liraglutide (IDegLira). Diabetes Care. 2014;37(11):2926-33. 